\title{
Understanding the mechanism of the decomposition reaction of nitroethyl benzoate through the Molecular Electron Density Theory
}

\author{
Agnieszka Kącka-Zych ${ }^{1} \cdot$ Luis R. Domingo $^{2} \cdot$ Mar Ríos-Gutiérrez $^{2} \cdot$ \\ Radomir Jasiński ${ }^{1}$
}

Received: 26 July 2017 / Accepted: 9 October 2017 / Published online: 20 October 2017

(c) The Author(s) 2017. This article is an open access publication

\begin{abstract}
The molecular mechanism of the decomposition reaction of nitroethyl benzoate (NEB) 1 yielding nitroethylene $\mathbf{2}$ and benzoic acid $\mathbf{3}$ has been studied within the Molecular Electron Density Theory (MEDT) using DFT methods at the B3LYP/6-31G(d) computational level. This decomposition reaction takes place through a one-step mechanism. Bonding Evolution Theory (BET) analysis of this reaction provides a complete characterisation of the electron density changes along the reaction. The reaction begins through the synchronous rupture of the $\mathrm{O}-\mathrm{C}$ and $\mathrm{C}-\mathrm{H}$ single bonds of NEB 1. Interestingly, while the rupture of the $\mathrm{O}-\mathrm{C}$ single bond takes place heterolytically, that of the C5-H6 one takes place homolytically, yielding the formation of a pseudoradical hydrogen atom. These changes, which demand a high energy cost of $37.1 \mathrm{kcal} \mathrm{mol}^{-1}$, are responsible for the high activation energy associated with this decomposition reaction. Formation of the $\mathrm{C}-\mathrm{C}$ double bond present in nitroethylene 2 takes place at the end of the reaction. The six differentiated phases in which the IRC associated with this reaction is divided clearly point out its non-concerted nature, thus ruling out the proposed pericyclic mechanism. This reaction, whose associated TS presents a more or less distorted six-membered cyclic structure in which all atoms
\end{abstract}

Agnieszka Kącka-Zych

akacka@chemia.pk.edu.pl

Mar Ríos-Gutiérrez

rios@utopia.uv.es

1 Institute of Organic Chemistry and Technology, Cracow University of Technology, Warszawska 24, 31-155 Cracow, Poland

2 Department of Organic Chemistry, University of Valencia, Dr. Moliner 50, 46100 Burjassot, Valencia, Spain may not necessarily be bound, is categorised as a pseudocyclic reaction.

Keywords Thermal elimination · Nitroalkenes · Molecular electron density theory $\cdot$ Bonding evolution theory $\cdot$ Electron localisation function $\cdot$ Pseudocyclic reactions

\section{Introduction}

The thermal decomposition of alkyl esters to produce alkenes and carboxylic acids is a well-established process experimentally investigated a great number of times [1-5]. Detailed reviews that report on many studies involving the kinetics and mechanism of the decomposition of esters are available $[4,5]$.

Conjugated nitroalkenes (CNAs) have proved to be a valuable group of reactants in organic chemistry. Their strong electrophilic character makes them important precursors towards a wide variety of target molecules. They are useful compounds applied, e.g. in syntheses of many four-, fiveand six-membered compounds in cycloaddition reactions [6-11]. Applications of nitroalkenes in organic synthesis are largely due to their ease of conversion into a variety of functionalities. Moreover, a considerable number of nitroalkenes exhibits remarkable biological activity [12-15].

There are many strategies for the preparation of CNAs. However, the most universal method is that based on the decomposition of nitroalkyl esters. The thermal decomposition of carboxylic esters to yield an alkene and a carboxylic acid has been studied since 1883 [16, 17]. Recently, we theoretically studied the thermal decomposition of nitroalkyl esters $[18,19]$. Thus, for the thermal decomposition of nitroethyl benzoate (NEB) $\mathbf{1}$ yielding nitroethylene $\mathbf{2}$ and 
benzoic acid $\mathbf{3}$, we proposed [19] that this process could be characterised by a one-step two-stage mechanism [20] (see Scheme 1).

This decomposition reaction presents a high activation energy, $42.5 \mathrm{kcal} \mathrm{mol}^{-1}$, the reaction being endothermic by $16.3 \mathrm{kcal} \mathrm{mol}^{-1}$. The geometry of the transition state structure (TS) given in Fig. 1 shows that it presents a distorted six-membered rearrangement in which the length of the breaking O-C single bond is $1.750 \AA$, while the distances between the $\mathrm{H}$ atom and the $\mathrm{C}$ and $\mathrm{O}$ atoms are 1.569 and $1.095 \AA$ A respectively [19].

Contemporary determination of the principles controlling a reaction mechanism is closely tied with the progress of quantum chemistry. One of the fundamental goals for understanding a given chemical rearrangement is to analyse the changes of quantum mechanical observables such as the electron density along the reaction pathway. This approach enables a comprehensive picture of the chemical reactivity in terms of how and when chemical events, e.g. bond rupture and formation processes, will take place. To this end, the Bonding Evolution Theory (BET) [21], which combines the topological analysis of the electron localisation function (ELF) [22] with the mathematical Catastrophe Theory (CT), was proposed [23-25]. BET has proved to be a useful quantum chemical tool for the study of reaction mechanisms [26-29].

Very recently, Domingo proposed the Molecular Electron Density Theory (MEDT) [30], in which changes in the electron density, but not molecular orbital (MO) interactions such as the Frontier Molecular Orbital (FMO) theory proposed [31], are responsible for the reactivity in organic chemistry. Note that the electron density obtained from the wavefunction is the unique physically observable. Within MEDT, besides an exhaustive exploration and characterisation of the reaction paths associated with the studied reaction, analysis of the CDFT reactivity indices [32,33], as well as quantum chemical tools based on the topological analysis

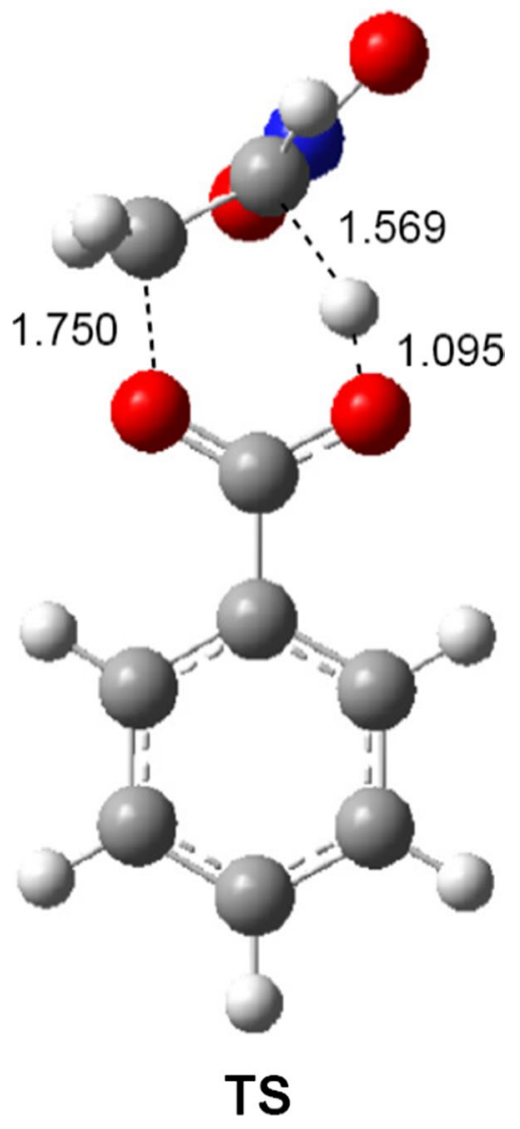

Fig. 1 B3LYP/6-31G(d) geometry of TS. Distances are given in angstroms, A [19]

of the molecular electron density such as the ELF [22], the Quantum Theory of Atoms In Molecules (QTAIM) [34] and Non-Covalent Interactions (NCI) [35], are used in order to study the reactivity in organic chemistry.

It is stay accepted that decomposition reactions of alkyl carboxylates are essentially a pericyclic process [36]. Nonetheless, the last reports $[37,38]$ based on the analysis of the
Scheme 1 General scheme of decomposition reaction of nitroethyl benzoate (NEB) 1. B3LYP/6-31G(d) relative energies with respect to NEB $\mathbf{1}$ are given in $\mathrm{kcal} \cdot \mathrm{mol}^{-1}$. Note that broken lines at TS within the breaking and forming regions do not refer to a conjugated cyclic pattern but only indicate the bonds that are going to break or form

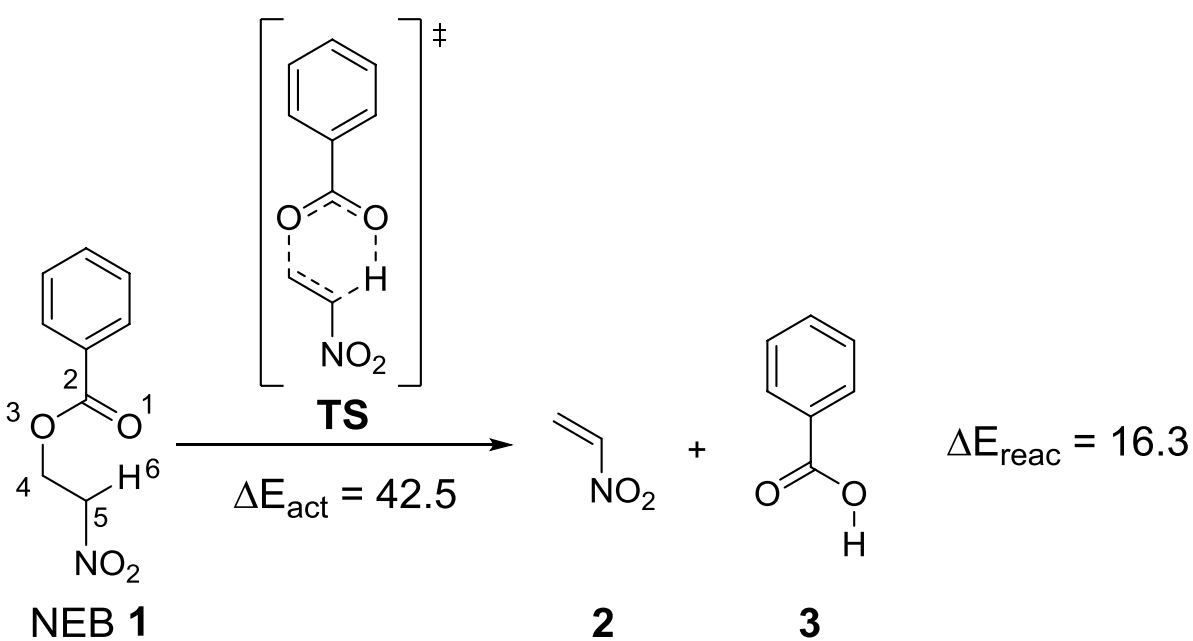


evolution of the electron density along a reaction involving a cyclic arrangement of nuclei, i.e. pseudocyclic reactions [39], reveal that the pericyclic mechanism does not exist as the bonding changes are not concerted [40]. In this work, as a continuation of the quantum chemical study about the decomposition reaction of nitroethyl carboxylates [18, 19], an MEDT study of the decomposition process of NEB $\mathbf{1}$ is performed in order to establish the molecular mechanism of this decomposition reaction and the nature of the electronic rearrangement along it.

\section{Computational details}

Calculations were performed using the Prometheus computer cluster in the CYFRONET regional computer centre in Cracow and the cluster of Domingo's group. All calculations were carried out with the GAUSSIAN 09 package [41]. DFT calculations were performed using the B3LYP [42, 43] functional together with the 6-31G(d) basis set [44]. The stationary points were characterised by frequency calculations in order to verify the number of imaginary frequencies (zero for local minima and one for TSs). The IRC [45] paths, computed using the second order González-Schlegel integration method [46, 47], were traced in order to obtain the energy profiles connecting TS to the two associated minima of the proposed mechanism.

ELF studies were performed with the TopMod [48] programme using the corresponding gas phase B3LYP/6$31 \mathrm{G}(\mathrm{d})$ monodeterminantal wavefunctions. For the BET study, the corresponding gas phase reaction channel was followed by performing the topological analysis of the ELF for 855 nuclear configurations along the IRC path. ELF calculations were computed over a grid spacing of 0.1 a.u. for each structure, and ELF localisation domains were obtained for an ELF value of 0.75 .

\section{Results and discussion}

The present theoretical study has been divided into three sections: i) in Sect. 3.1, an ELF topological analysis and a natural population analysis (NPA) of the reagent NEB 1 are performed in order to characterise its electronic structure; ii) in Sect. 3.2, a BET study of the decomposition reaction of NEB 1 is performed in order to characterise the molecular mechanism of this intramolecular process; and finally, iii) in Sect. 3.3, an MEDT study of the decomposition reaction of NEB 1 based, on the one hand, the BET study, and, on the other hand, the analysis of the energies related to the different bonding changes taking place along to the reaction, is given with the aim of providing an explanation of its activation energy.

\subsection{ELF and NPA characterisation of the electronic structure of NEB 1}

One appealing procedure that provides a straightforward connection between the electron density distribution and the chemical structure is the quantum chemical analysis of Becke and Edgecombe's ELF [22]. Therefore, in order to characterise the electronic structure of NEB 1, a topological analysis of the ELF was first performed. ELF localisation domains and their attractor positions, together with the most representative valence basin populations, as well as the proposed ELF-based Lewis structure, together with the natural atomic charges, are shown in Fig. 2.

ELF topological analysis of NEB 1 shows the presence of three monosynaptic basins over the $\mathrm{O} 1$ and $\mathrm{O} 3$ oxygen atoms, $\mathrm{V}(\mathrm{O} 1), \mathrm{V}^{\prime}(\mathrm{O} 1)$ and $\mathrm{V}(\mathrm{O} 3)$, integrating total electron populations of 5.36e $(\mathrm{O} 1)$ and $4.60 \mathrm{e}(\mathrm{O} 3)$, four disynaptic basins $\mathrm{V}(\mathrm{O} 1, \mathrm{C} 2), \mathrm{V}(\mathrm{C} 2, \mathrm{O} 3), \mathrm{V}(\mathrm{O} 3, \mathrm{C} 4)$ and $\mathrm{V}(\mathrm{C} 4, \mathrm{C} 5)$, integrating $2.39 \mathrm{e}, 1.61 \mathrm{e}, 1.39 \mathrm{e}$ and $1.95 \mathrm{e}$, and one $\mathrm{V}(\mathrm{C} 5$, H6) protonated basin with a population of 2.07e.

Within the ELF context, monosynaptic basins are associated with non-bonding regions, disynaptic basins are related to bonding regions and protonated basins correspond to bonding regions involving hydrogen atoms [49]. Thus, within the Lewis bonding model $[50,51]$, the $\mathrm{V}(\mathrm{O} 1)$, $\mathrm{V}^{\prime}(\mathrm{O} 1)$ and $\mathrm{V}(\mathrm{O} 3)$ monosynaptic basins can be associated with $\mathrm{O} 1$ and $\mathrm{O} 3$ oxygen lone pairs, the $\mathrm{V}(\mathrm{O} 1, \mathrm{C} 2), \mathrm{V}(\mathrm{C} 2$, $\mathrm{O} 3)$ and $\mathrm{V}(\mathrm{C} 5, \mathrm{C} 4)$ disynaptic basin with $\mathrm{O} 1-\mathrm{C} 2, \mathrm{C} 2-\mathrm{C} 3$ and $\mathrm{C} 4-\mathrm{C} 5$ single bonds, and the $\mathrm{V}(\mathrm{O} 3, \mathrm{C} 4)$ disynaptic and $\mathrm{V}(\mathrm{C} 5, \mathrm{H} 6)$ protonated basins with the $\mathrm{O} 3-\mathrm{C} 4$ and $\mathrm{C} 5-\mathrm{H} 6$ bonds that are going to be broken along the decomposition reaction of NEB 1 (see the proposed ELF-based Lewis structure in Fig. 2). Note, however, that the $\mathrm{O} 1$ and $\mathrm{O} 3$ oxygen "lone pairs" cannot actually be considered so. Interestingly, the $\mathrm{V}(\mathrm{O} 1, \mathrm{C} 2)$ population, which permits to categorise the $\mathrm{O} 1-\mathrm{C} 2$ bonding region as a single one, and the population of the $\mathrm{O} 1$ oxygen monosynaptic basins, ca. 5e, as well as the depopulated O3-C4 single bond, contrast with the common bonding pattern represented for NEB 1 (see the Lewis structures in Fig. 2). It is also worth mentioning that the latter feature may, at first glance, suggest a high feasibility for the rupture of the $\mathrm{O} 3-\mathrm{C} 4$ single bond.

Once the bonding pattern of NEB 1 was established, the charge distribution was analysed through an NPA [47, 48]. Natural atomic charges of the most relevant atoms are shown together with the proposed ELF-based Lewis structure given in Fig. 2. NPA of NEB 1 reveals that while the $\mathrm{O} 1$ and $\mathrm{O} 3$ oxygen atoms gather the higher negative charges of the six-membered framework involved in the reaction, $-0.61 \mathrm{e}$ $(\mathrm{O} 1)$ and $-0.56 \mathrm{e}(\mathrm{O} 3)$, the $\mathrm{C} 5$ carbon is half as negatively charged, $-0.35 \mathrm{e}$, and the $\mathrm{C} 4$ carbon only slightly, $-0.14 \mathrm{e}$. On the other hand, while the carbonyl $\mathrm{C} 2$ carbon presents a relatively high positive charge, $0.82 \mathrm{e}$, the $\mathrm{H} 6$ hydrogen is 


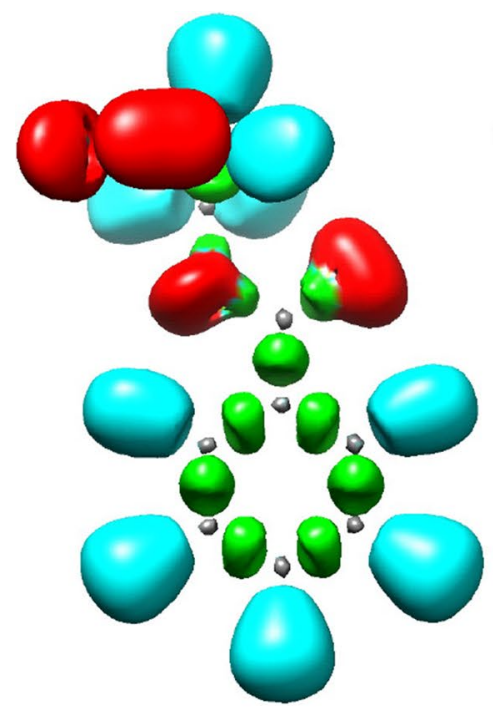

(a)

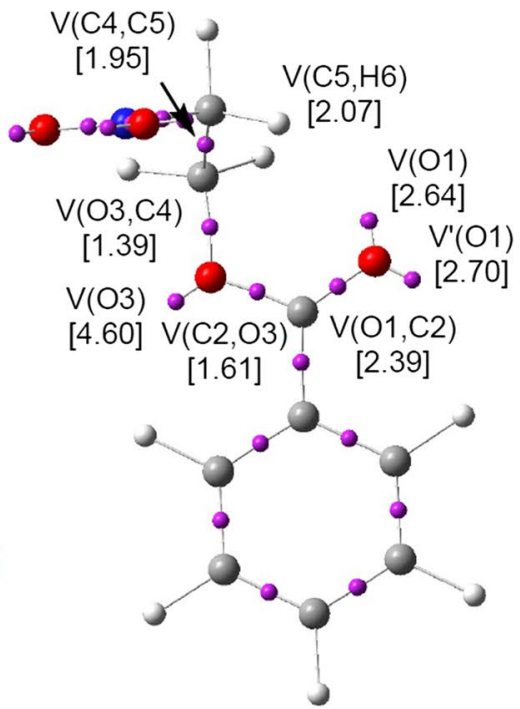

(b)

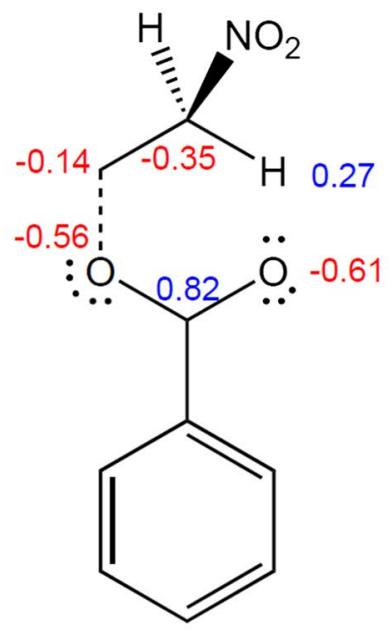

(c)

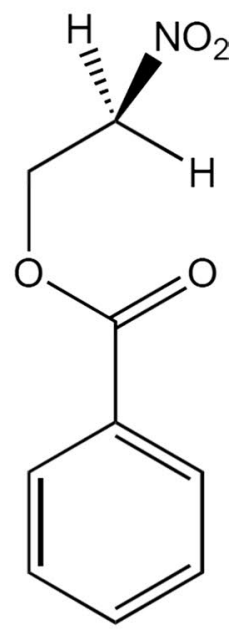

(d)
Fig. 2 a ELF localisation domains of NEB 1, represented at an isosurface value of ELF $=0.75 ; \mathbf{b}$ ELF basin attractor positions, together with the most representative valence basin populations; c the proposed ELF-based Lewis structures, together with the natural atomic

positively charged by 0.27 e. Thus, while the $\mathrm{O} 1, \mathrm{O} 3, \mathrm{C} 4$ and $\mathrm{C} 5$ atoms gather negative charges, only the $\mathrm{C} 2$ carbon and the H6 hydrogen are positively charged.

Considering the set of resonance Lewis structures of NEB 1, neither the $\mathrm{O} 3$ oxygen nor the $\mathrm{C} 4$ or $\mathrm{C} 5$ carbons would never somehow gather negative charges. Consequently, the electronic structure of NEB $\mathbf{1}$ arising from both the topological analysis of the ELF and the NPA is quite different to that expected (see Fig. 2). Note that the charge distribution obtained through the NPA is the consequence of the asymmetric electron density delocalisation within a molecule resulting from the presence of different nuclei in the molecule, rather than the consequence of the resonance Lewis structures.

\subsection{BET study of the decomposition reaction of NEB 1}

When trying to achieve a better understanding of the mechanism of organic reactions, the so-called BET [21] has proven to be a very useful methodological tool. This quantum chemical methodology makes it possible to understand the bonding changes along a reaction path and, thus, to establish the nature of the electronic rearrangement associated with a given molecular mechanism [26-29].

The populations, among other relevant parameters, of the most significant ELF valence basins (those associated with the bonding regions directly involved in the reaction) of the selected points of the IRC, Pi, defining the different topological phases are gathered in Table 1, while ELF localisation charges, obtained through an NPA; and $\mathbf{d}$ the commonly used Lewis representation. Negative charges are coloured in red and positive charges are coloured in blue. ELF valence basin population and natural atomic charges are given in average number of electrons, $\mathbf{e}$

domains and their attractor positions for the points involved in the bond formation processes are shown in Fig. 3.

The long Phase I (see Fig. 4), $2.24 \AA \geq \mathrm{d}(\mathrm{O} 1-\mathrm{H} 6)>1.52 \AA$, $1.44 \AA \leq \mathrm{d}(\mathrm{O} 3-\mathrm{C} 4)<1.66 \AA$ and $1.09 \AA \leq \mathrm{d}(\mathrm{C} 5-\mathrm{H} 6)<1.13 \AA$, begins at $\mathbf{P 0}$, which is the discontinue point of the IRC from TS towards the isolated reagent NEB 1. The ELF picture of $\mathbf{P 0}$ usually resembles that of the separated reagents. Thus, ELF topological analysis of $\mathbf{P 0}$ only reveals slight changes in the ELF valence basin electron populations of NEB 1 (see Table 1 and Fig. 2). Along this phase, the population of the $\mathrm{V}(\mathrm{O} 1, \mathrm{C} 2)$ disynaptic basin progressively decreases, while that of the $\mathrm{V}(\mathrm{C} 2, \mathrm{O} 3)$ and $\mathrm{V}(\mathrm{C} 4, \mathrm{C} 5)$ gradually increases, a behaviour maintained until the end of the reaction at MC. The V(C5, H6) protonated basin is also slightly depopulated. Note that along this phase, the $\mathrm{O} 1$ and $\mathrm{H} 6$ atoms remain non-bound.

Phase II, $1.52 \AA \geq \mathrm{d}(\mathrm{O} 1-\mathrm{H} 6)>1.35 \AA$, $1.66 \AA \leq \mathrm{d}(\mathrm{O} 3-\mathrm{C} 4)<1.70 \AA$ and $1.13 \AA \leq \mathrm{d}(\mathrm{C} 5-\mathrm{H} 6)<1.28$ $\AA$, begins at P1. At this point, the first most relevant topological change along the reaction path takes place; together with the disappearance of the $\mathrm{V}(\mathrm{O} 3, \mathrm{C} 4)$ disynaptic basin present in the previous phase by means of a fold $F$ catastrophe, a new $\mathrm{V}^{\prime}(\mathrm{O} 3)$ monosynaptic basin is created with an initial population of $1.04 \mathrm{e}$, strongly increasing the non-bonding total electron density of the $\mathrm{O} 3$ oxygen to 5.79e. This significant topological change indicates that the rupture of the $\mathrm{O} 3-\mathrm{C} 4$ single bond begins at an $\mathrm{O} 3-\mathrm{C} 4$ distance of ca. $1.66 \AA$, resulting in the formation of a $\mathrm{O} 3$ pseudoradical centre. In this phase, the benzoate framework is formed. 
Table 1 ELF valence basin populations, distances of the breaking and forming bonds, relative ${ }^{\mathrm{a}}$ electronic energies of the IRC points, $\mathbf{P 0}-\mathbf{P 5}$, defining the six phases characterising the molecular mechanism of the decomposition of NEB $\mathbf{1}$. The stationary points $\mathbf{1}, \mathbf{T S}$ and $\mathbf{M C}$ are also included. Distances are given in angstroms, $\AA$, electron populations in average number of electrons, e, and relative energies in $\mathrm{kcal} \mathrm{mol}^{-1}$

\begin{tabular}{|c|c|c|c|c|c|c|c|c|c|}
\hline Points & 1 & P0 & $\mathbf{P 1}$ & $\mathbf{P 2}$ & P3 & P4 & P5 & MC & TS \\
\hline Catastrophes & & & $\mathrm{F}$ & $\mathrm{C}^{\dagger}$ & $\mathrm{C}$ & $\mathrm{F}$ & $\mathrm{C}^{\dagger}$ & & \\
\hline Phases & & & I & II & III & IV & $\mathrm{V}$ & VI & \\
\hline $\mathrm{d}(\mathrm{O} 3-\mathrm{C} 4)$ & 1.435 & 1.436 & 1.663 & 1.696 & 1.761 & 1.997 & 2.006 & 3.288 & 1.750 \\
\hline d(C5-H6) & 1.088 & 1.086 & 1.133 & 1.283 & 1.596 & 1.848 & 1.856 & 2.834 & 1.569 \\
\hline d(O1-H6) & 2.707 & 2.243 & 1.518 & 1.353 & 1.077 & 0.991 & 0.990 & 0.976 & 1.095 \\
\hline$\Delta \mathrm{E}^{\mathrm{a}}$ & -5.4 & 0.0 & 22.0 & 30.4 & 37.1 & 30.8 & 30.5 & 10.9 & 37.1 \\
\hline $\mathrm{V}(\mathrm{O} 1, \mathrm{C} 2)$ & 2.39 & 2.37 & 2.20 & 2.10 & 1.95 & 1.71 & 1.71 & 1.64 & 1.91 \\
\hline $\mathrm{V}(\mathrm{C} 2, \mathrm{O} 3)$ & 1.61 & 1.59 & 1.76 & 1.87 & 2.07 & 2.29 & 2.28 & 2.37 & 2.04 \\
\hline $\mathrm{V}(\mathrm{C} 4, \mathrm{C} 5)$ & 1.95 & 1.99 & 2.06 & 2.14 & 2.51 & 3.60 & 1.68 & 1.74 & 2.47 \\
\hline $\mathrm{V}^{\prime}(\mathrm{C} 4, \mathrm{C} 5)$ & & & & & & & 1.92 & 1.79 & \\
\hline $\mathrm{V}(\mathrm{O} 1)$ & 2.64 & 2.69 & 2.60 & 2.20 & & & & & 1.35 \\
\hline $\mathrm{V}^{\prime}(\mathrm{O} 1)$ & 2.70 & 2.67 & 2.93 & 3.32 & 4.36 & 4.40 & 4.39 & 4.45 & 4.13 \\
\hline $\mathrm{V}(\mathrm{O} 3)$ & 4.60 & 4.70 & 4.75 & 4.62 & 4.07 & 3.15 & 3.14 & 2.62 & 4.17 \\
\hline $\mathrm{V}^{\prime}(\mathrm{O} 3)$ & & & 1.04 & 1.08 & 1.41 & 2.21 & 2.23 & 2.71 & 1.35 \\
\hline V(C5) & & & & 1.16 & 1.15 & & & & 1.19 \\
\hline V(H6) & & & & 0.73 & & & & & 0.58 \\
\hline $\mathrm{V}(\mathrm{O} 3, \mathrm{C} 4)$ & 1.39 & 1.36 & & & & & & & \\
\hline V(C5, H6) & 2.07 & 2.04 & 1.96 & & & & & & \\
\hline $\mathrm{V}(\mathrm{O} 1, \mathrm{H} 6)$ & & & & & 1.65 & 1.79 & 1.80 & 1.69 & \\
\hline
\end{tabular}

${ }^{\text {a }}$ Relative to the first point of the IRC, P0
Phase III, $1.35 \AA \geq \mathrm{d}(\mathrm{O} 1-\mathrm{H} 6)>1.08 \AA$, $1.70 \AA \leq \mathrm{d}(\mathrm{O} 3-\mathrm{C} 4)<1.76 \AA$ and $1.28 \AA \leq \mathrm{d}(\mathrm{C} 5-\mathrm{H} 6)<1.60 \AA$, begins at P2. At this point, the second most relevant topological change along the reaction path occurs; the $\mathrm{V}(\mathrm{C} 5, \mathrm{H} 6)$ protonated basin present at the previous phase splits into two new $\mathrm{V}(\mathrm{C} 5)$ and $\mathrm{V}(\mathrm{H} 6)$ monosynaptic basins integrating $1.16 \mathrm{e}$ and 0.73 e (see P1 and TS in Fig. 3). This significant topological change, associated with a cusp $C$ catastrophe, indicates that the rupture of the $\mathrm{C} 5-\mathrm{H} 6$ bond takes place closely after the $\mathrm{O} 3-\mathrm{C} 4$ one, at a C5-H6 distance of ca. $1.28 \AA$, resulting in the formation of a C5 pseudoradical centre and a free pseudoradical H6 hydrogen. It should be emphasised that along this phase, the population of the two $\mathrm{V}(\mathrm{O} 1)$ and $\mathrm{V}^{\prime}(\mathrm{O} 1)$ monosynaptic basins is redistributed between them in such a manner that at the end of this phase both basins end up with 1.30e and 4.15e. In this phase, the TS of the reaction, TS, $\mathrm{d}(\mathrm{O} 1-\mathrm{H} 6)=1.095 \AA$, $\mathrm{d}(\mathrm{O} 3-\mathrm{C} 4)=1.750$ and $\mathrm{d}(\mathrm{C} 5-\mathrm{H} 6)=1.569 \AA$, is found, presenting only slight variations in the ELF basin populations with respect to the topological features of $\mathbf{P 2}$ (see Table 1).

Along Phases I-III, the two V(O3, C4) disynaptic and $\mathrm{V}(\mathrm{C} 5, \mathrm{H} 6)$ protonated basins disappear, while the $\mathrm{V}(\mathrm{O} 1$, $\mathrm{C} 2$ ) disynaptic basin is being depopulated and those related to the $\mathrm{C} 2-\mathrm{C} 3$ and $\mathrm{C} 4-\mathrm{C} 5$ bonding regions are being populated. Thus, the bonding changes taking place along Phases $I-I I I$, which are mainly associated with the rupture of the two O3-C4 and C5-H6 bonds, demand a high energy cost (EC) of ca. $37.1 \mathrm{kcal} \mathrm{mol}^{-1}$ (see Table 1).
Phase IV, $1.08 \AA \geq \mathrm{d}(\mathrm{O} 1-\mathrm{H} 6)>0.99 \AA$, $1.76 \AA \leq \mathrm{d}(\mathrm{O} 3-\mathrm{C} 4)<2.00 \AA$ and $1.60 \AA \leq \mathrm{d}(\mathrm{C} 5-\mathrm{H} 6)<1.85 \AA$, begins at P3. At this point, the third most relevant topological change along the reaction path takes place; together with the strong depopulation of the $\mathrm{V}(\mathrm{O} 1)$ and $\mathrm{V}^{\prime}(\mathrm{O} 1)$ monosynaptic basins by 1.16e, so that both merge into one new $\mathrm{V}(\mathrm{O} 1)$ monosynaptic basin integrating $4.36 \mathrm{e}$, and the disappearance of the $\mathrm{V}(\mathrm{H} 6)$ monosynaptic basin, a new $\mathrm{V}(\mathrm{O} 1, \mathrm{H} 6)$ protonated basin is created with an initial population of 1.65e through the merger of two $\mathrm{V}(\mathrm{O} 1)$ and $\mathrm{V}(\mathrm{H} 6)$ monosynaptic basins (see P3 in Fig. 3). This topological change, associated with a cusp $C$ catastrophe, reveals that the formation of the new O1-H6 single bond begins at an O1-H6 distance of ca. 1.08 by sharing part of the non-bonding electron density of the $\mathrm{O} 1$ oxygen with the pseudoradical $\mathrm{H} 6$ hydrogen. The $\mathrm{V}(\mathrm{C} 5)$ monosynaptic basin is still present at $\mathbf{P 3}$ with a population of 1.15e, but progressively decreases along Phase $I V$ until $0.55 \mathrm{e}$. As a consequence, the population of the adjacent $\mathrm{V}(\mathrm{C} 4, \mathrm{C} 5)$ disynaptic basin, integrating $2.51 \mathrm{e}$ at $\mathbf{P 3}$, increases in such a manner that the $\mathrm{C} 4-\mathrm{C} 5$ bonding region gradually acquires double bond character (see P3's Lewis structure in Table 2).

Along Phase IV, a new $\mathrm{V}(\mathrm{O} 1, \mathrm{H} 6)$ protonated basin is created and further populated, while the other $\mathrm{V}(\mathrm{O} 1, \mathrm{C} 2)$, $\mathrm{V}(\mathrm{C} 2, \mathrm{O} 3)$ and $\mathrm{V}(\mathrm{C} 4, \mathrm{C} 5)$ disynaptic basins experience the same changes as in previous phases. The electron density of the $\mathrm{V}(\mathrm{C} 5)$ monosynaptic basin gradually decreases, being redistributed into the adjacent $\mathrm{V}(\mathrm{C} 4, \mathrm{C} 5)$ disynaptic basin provoking its population. Thus, the bonding changes taking place along Phase $I V$, which are mainly associated 


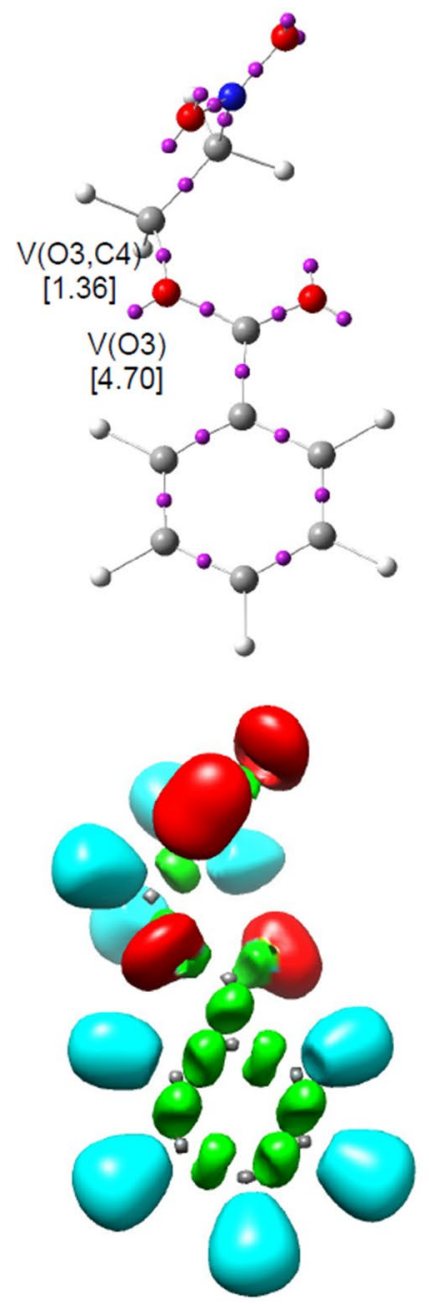

PO
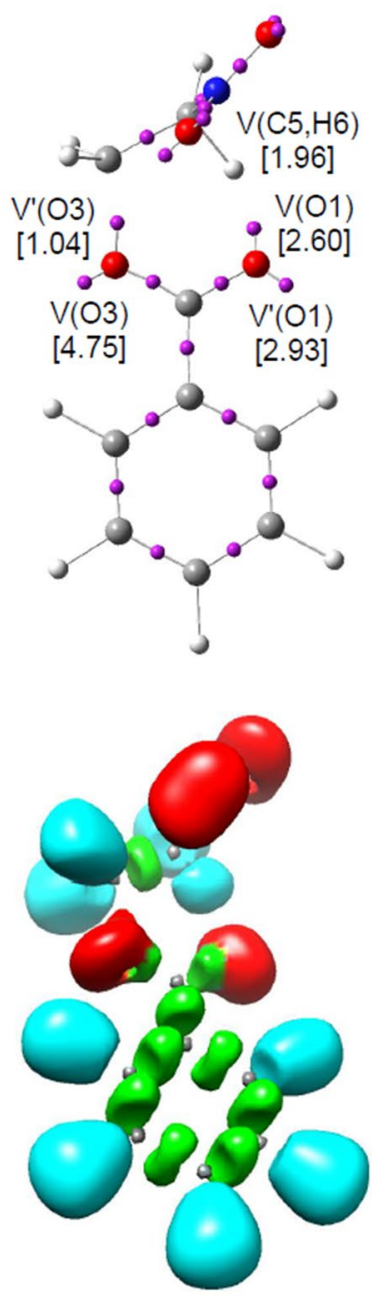

P1
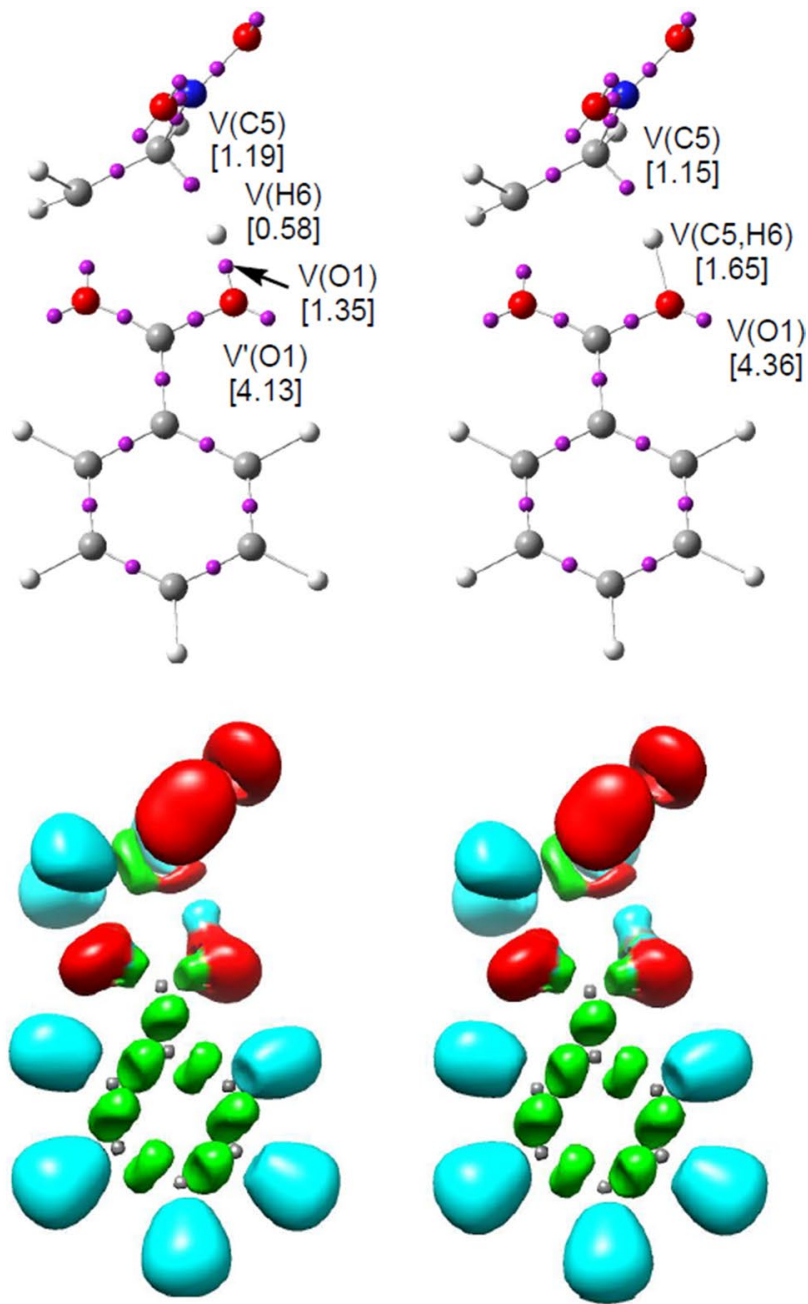

TS

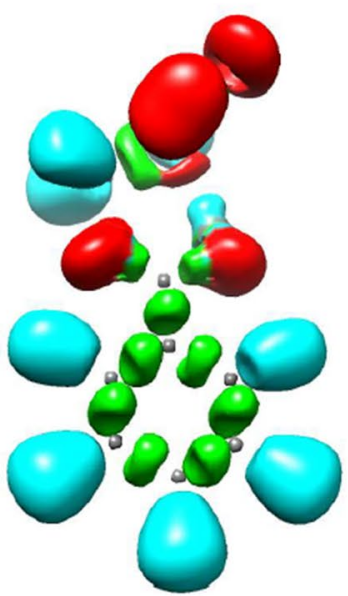

P3

Fig. 3 ELF localisation domains, represented at isosurface values of ELF $=0.75$, together with their attractor positions the points of the IRC defining Phases I and II, involved in the rupture of the O3$\mathrm{C} 4$ and $\mathrm{C} 5-\mathrm{H} 6$ bonds, and TS and Phase IV involved in the rupture

with the formation of the new $\mathrm{O} 1-\mathrm{H} 6$ bond, release a molecular relaxation energy of ca. $6.3 \mathrm{kcal} \mathrm{mol}^{-1}$ (see Table 1).

Phase $V, 0.991 \AA \geq \mathrm{d}(\mathrm{O} 1-\mathrm{H} 6)>0.990 \AA$, $2.00 \AA \leq \mathrm{d}(\mathrm{O} 3-\mathrm{C} 4)<2.01 \AA$ and $1.85 \AA \leq \mathrm{d}(\mathrm{C} 5-\mathrm{H} 6)<1.86 \AA$, begins at $\mathbf{P 4}$. At this point, established by a fold $F$ catastrophe, while the V(C5) monosynaptic basin disappears, the $\mathrm{V}(\mathrm{C} 4, \mathrm{C} 5)$ disynaptic basin reaches $3.60 \mathrm{e}$ as a consequence of the redistribution of the population of the former basin into the latter. This high electron density permits to characterise the $\mathrm{C} 4-\mathrm{C} 5$ bonding region as a double bond at $\mathbf{P 4}$ (see P4's Lewis structure in Table 2). On the other hand, the non-bonding electron density of the $\mathrm{O} 3$ oxygen atom is also redistributed between the two $\mathrm{V}(\mathrm{O} 3)$ and $\mathrm{V}^{\prime}(\mathrm{O} 3)$ monosynaptic basins, integrating $3.15 \mathrm{e}$ and $2.21 \mathrm{e}$.

of the $\mathrm{C} 5-\mathrm{H} 6$ bond and the formation of the O1-H6 bond along the decomposition reaction of NEB 1. The electron populations, in e, are given in brackets

Finally, the long Phase VI (see Fig. 4), $0.99 \AA \geq \mathrm{d}(\mathrm{O} 1-\mathrm{H} 6) \geq 0.98 \AA, 2.01 \AA \leq \mathrm{d}(\mathrm{O} 3-\mathrm{C} 4) \leq 3.29 \AA$ and $1.86 \AA \leq \mathrm{d}(\mathrm{C} 5-\mathrm{H} 6) \leq 2.83 \AA$, begins at $\mathbf{P 5}$ and ends at molecular complex MC, which is a minimum in the reaction path from TS towards the separated products, nitroethylene $\mathbf{2}$ and benzoic acid $\mathbf{3}$. At P5, the only notable topological change is the split of the single $\mathrm{V}(\mathrm{C} 4, \mathrm{C} 5)$ disynaptic basin present in the nitroethylene framework at the previous phase into two new $\mathrm{V}(\mathrm{C} 4, \mathrm{C} 5)$ and $\mathrm{V}^{\prime}(\mathrm{C} 4, \mathrm{C} 5)$ disynaptic basins, integrating $1.68 \mathrm{e}$ and $1.92 \mathrm{e}$, by means of a cusp $C^{\dagger}$ catastrophe. This topological change is simply the consequence of an electron density reorganisation within the $\mathrm{C} 4-\mathrm{C} 5$ double bond region, as the total population has not varied.

Along Phases $V$ and $V I$, the population of the disynaptic basins corresponding to the $\mathrm{C} 4-\mathrm{C} 5$ bonding region considerably increases, while the population variations of 


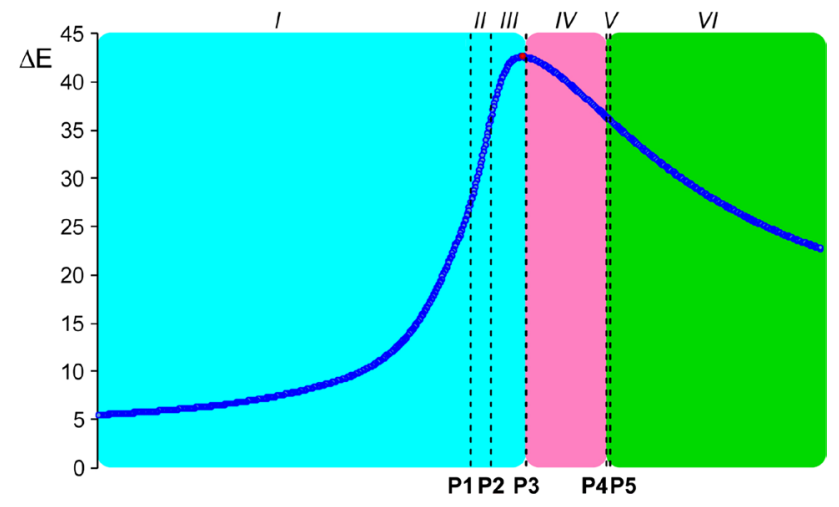

Fig. 4 Phases in which the IRC associated with the decomposition reaction of NEB $\mathbf{1}$ is topologically divided. The red point indicates the position of TS, black broken lines separate the phases defined by points $\mathbf{P i}$ along the IRC, while blue, pink and green areas represent the different groups in which the reaction is mechanistically divided. Relative energies $\left(\Delta \mathrm{E}\right.$, in $\left.\mathrm{kcal} \mathrm{mol}^{-1}\right)$ are given with respect to the more stable conformational isomer of NEB 1

the other basins follow the same trend that along previous phases. Consequently, the bonding changes taking place along Phases $V$ and VI, which are mainly associated with the formation of the C4-C5 double bond of nitroethylene 2 and the complete reorganisation to form the final structures of nitroethylene $\mathbf{2}$ and benzoic acid $\mathbf{3}$, release the maximum MRE along the reaction, ca. $19.9 \mathrm{kcal} \mathrm{mol}^{-1}$ (see Table 1).

At MC, d $(\mathrm{O} 1-\mathrm{H} 6)=0.967, \mathrm{~d}(\mathrm{O} 3-\mathrm{C} 4)=3.288 \AA$ and $\mathrm{d}(\mathrm{C} 5-\mathrm{H} 6)=2.834 \AA$, only slight variations in the ELF basin populations with respect to those calculated at $\mathbf{P 5}$ are observed. After the increase of the population of the monosynaptic basins associated with the $\mathrm{O} 3$ oxygen due to the rupture of the $\mathrm{O} 3-\mathrm{C} 4$ single bond, they have been depopulated to 5.33e towards the $\mathrm{V}(\mathrm{C} 2, \mathrm{O} 3)$ disynaptic basin, which reaches $2.37 \mathrm{e}$. Similarly, the monosynaptic basins associated with the $\mathrm{O} 1$ oxygen end up with $4.45 \mathrm{e}$ after their early population coming from the $\mathrm{V}(\mathrm{O} 1, \mathrm{C} 2)$ disynaptic basin and their next depopulation towards the new $\mathrm{V}(\mathrm{O} 1, \mathrm{H} 6)$ protonated basin, which integrates $1.69 \mathrm{e}$.

From this BET study, the molecular mechanism of the decomposition reaction of NEB 1 can be summarised as follows (see Lewis structures in Table 2): i) this reaction is topologically characterised by six differentiated phases, emphasising the non-concerted nature of the bonding changes taking place along the reaction; ii) the reaction begins with the depopulation of the $\mathrm{V}(\mathrm{O} 3, \mathrm{C} 4)$ disynaptic and $\mathrm{V}(\mathrm{C} 5$, H6) protonated basins, associated with the two O3-C4 and C5-H6 bonds that are going to be broken (Phases I-III), until they disappear (first the $\mathrm{V}(\mathrm{O} 3, \mathrm{C} 4)$ disynaptic basins and later the $\mathrm{V}(\mathrm{C} 5, \mathrm{H} 6)$ protonated one) giving rise to the formation of two $\mathrm{V}(\mathrm{C} 5)$ and $\mathrm{V}(\mathrm{H} 6)$ monosynaptic basins; iii) along Phases I-III, no bound six-membered cyclic structure exists. This fact, together with the non-concerted nature of the bonding changes, also allows ruling out the proposed pericyclic mechanism $[52,53]$ in which the bonding changes take place "in concert on a closed curve" assuming a bound cyclic structure; iv) as TS is found at the end of Phase III (see Fig. 4), the high activation energy associated with this decomposition reaction, $42.5 \mathrm{kcal} \mathrm{mol}^{-1}$ (see Table 1), can mainly be related to the disappearance of the mentioned $\mathrm{V}(\mathrm{O} 3, \mathrm{C} 4)$ and $\mathrm{V}(\mathrm{C} 5, \mathrm{H} 6)$ basins; v) TS consists of three different separated frameworks: the nitroethylene one, the benzoate one and a free pseudoradical hydrogen, precluding any conjugation and thus, any aromatic character of the TS [39]; vi) next, a new $\mathrm{V}(\mathrm{O} 1, \mathrm{H} 6)$ protonated basin, associated with an $\mathrm{O} 1-\mathrm{H} 6$ bond, is formed at Phase IV through the merger of two $\mathrm{V}(\mathrm{O} 1)$ and $\mathrm{V}(\mathrm{H} 6)$ monosynaptic basins at $\mathrm{d}_{\mathrm{O} 1-\mathrm{H} 6}=1.08 \AA$, and further populated releasing $6.3 \mathrm{kcal} \mathrm{mol}^{-1}$; and finally, vii) the V(C5) monosynaptic basin disappears towards the $\mathrm{V}(\mathrm{C} 4, \mathrm{C} 5)$ disynaptic basin, whose population suddenly increases and causes the split into two $\mathrm{V}(\mathrm{C} 4, \mathrm{C} 5)$ and $\mathrm{V}^{\prime}(\mathrm{C} 4, \mathrm{C} 5)$ disynaptic basins associated with the $\mathrm{C} 4-\mathrm{C} 5$ double bond of the nitroethylene framework.

\subsection{MEDT study of the decomposition reaction of NEB 1}

Within MEDT, the bonding changes are topologically and energetically analysed in order to understand the origin of the activation and the reaction energies associated with an organic reaction. In this section, the bonding changes arising from the BET study and their associated energy changes along the decomposition reaction of NEB $\mathbf{1}$ are summarised and described in a chemical fashion. Note that BET is a powerful tool to study the bonding changes along a reaction pathway, i.e. the molecular mechanisms, but neither the energies associated with the bonding changes nor energy differences between competitive reaction pathways are analysed within BET.

The sequential bonding changes resulting from the BET study of the decomposition reaction of NEB 1 are summarised in Table 2, together with a simplified representation of the molecular mechanism by ELF-based Lewis structures, while the phases and groups in which the corresponding IRC is topologically divided are represented in Fig. 4. Some appealing conclusions can be drawn from this MEDT study: i) the molecular mechanism of this reaction is topologically characterised by six differentiated phases which, in turn, can be reorganised in three Groups $A-C$ associated with significant chemical events (see Table 2 and Fig. 4). This fact clearly allows ruling out the pericyclic mechanism [53] proposed for this reaction; ii) Group A, which comprises Phases I-III and demands a high EC of ca. $37.1 \mathrm{kcal} \mathrm{mol}^{-1}$, is associated with the rupture of the $\mathrm{O} 3-\mathrm{C} 4$ and $\mathrm{C} 5-\mathrm{H} 6$ bonds of NEB 1; iii) the rupture of the $\mathrm{O} 3-\mathrm{C} 4$ and $\mathrm{C} 5-\mathrm{H} 6$ bonds, at $\mathrm{d}_{\mathrm{O}-\mathrm{C} 4}=1.66 \AA$ 
Table 2 Sequential bonding changes along the decomposition reaction of NEB 1, showing the equivalence between the topological characterisation of the different phases and the chemical processes occurring along them. Distances are given in angstroms, $\AA$, while the energies involved in each group, $\Delta \mathrm{E}$, are given in $\mathrm{kcal} \mathrm{mol}^{-1}$<smiles>O=[N+]([O-])[C@@H](O)C[C@H](O)c1ccccc1</smiles><smiles>CC(C)C1CCCCC1C(=O)c1ccccc1</smiles><smiles>C#CCCCCC</smiles><smiles>C[C@H](O)[N+](=O)[O-]</smiles><smiles>[Si]#[V]</smiles><smiles>C=CO[N+](=O)[O-]</smiles>
P3<smiles>CC(C)[N+](=O)[O-]</smiles>

P4

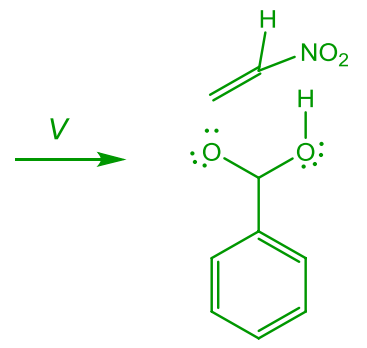

P5

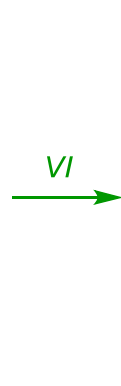

$\stackrel{\mathrm{VI}}{\longrightarrow}$

\begin{tabular}{|c|c|c|c|c|c|}
\hline Group & Phases & $\begin{array}{l}\mathrm{D}_{1}(\mathrm{O} 1-\mathrm{H} 6) \\
\mathrm{d}_{2}(\mathrm{O} 3-\mathrm{C} 4) \\
\mathrm{d}_{3}(\mathrm{C} 5-\mathrm{H} 6)\end{array}$ & $\Delta \mathrm{E}$ & Topological characterisation & Chemical process \\
\hline$A$ & $I-I I I(\mathbf{T S})$ & $\begin{array}{l}2.24 \geq \mathrm{d}_{1}>1.08 \\
1.44 \leq \mathrm{d}_{2}<1.76 \\
1.09 \leq \mathrm{d}_{3}<1.60\end{array}$ & 37.1 & Disappearance of the $\mathrm{V}(\mathrm{O} 3, \mathrm{C} 4)$ and $\mathrm{V}(\mathrm{C} 5, \mathrm{H} 6)$ basins & $\begin{array}{l}\text { Rupture of the } \mathrm{O} 3-\mathrm{C} 4 \text { and } \\
\text { C5-H6 bonds }\end{array}$ \\
\hline$B$ & IV & $\begin{array}{l}1.08 \geq \mathrm{d}_{1}>0.99 \\
1.76 \leq \mathrm{d}_{2}<2.00 \\
1.60 \leq \mathrm{d}_{3}<1.85\end{array}$ & -6.3 & Formation of the $\mathrm{V}(\mathrm{O} 1, \mathrm{H} 6)$ protonated basin & Formation of the $\mathrm{O} 1-\mathrm{H} 6$ bond \\
\hline$C$ & $V, V I$ & $\begin{array}{l}0.99 \geq \mathrm{d}_{1} \geq 0.98 \\
2.00 \leq \mathrm{d}_{2} \leq 3.29 \\
1.85 \leq \mathrm{d}_{3} \leq 2.83\end{array}$ & -19.9 & $\begin{array}{l}\text { Disappearance of the } \mathrm{V}(\mathrm{C} 5) \text { monosynaptic basin and } \\
\text { split of the } \mathrm{V}(\mathrm{C} 4, \mathrm{C} 5) \text { disynaptic basin into two } \mathrm{V}(\mathrm{C} 4 \text {, } \\
\text { C5) and } \mathrm{V}^{\prime}(\mathrm{C} 4, \mathrm{C} 5) \text { disynaptic basins }\end{array}$ & Formation of the $\mathrm{C} 4-\mathrm{C} 5$ double bond \\
\hline
\end{tabular}

and $\mathrm{d}_{\mathrm{C} 5-\mathrm{H} 6}=1.28 \AA$, is only slightly asynchronous and could be considered a synchronous process $\left(\Delta \mathrm{d}_{\mathrm{O} 3-\mathrm{C} 4}=0.03 \AA\right.$ and $\left(\Delta \mathrm{d}_{\mathrm{C} 5-\mathrm{H} 6}=0.15 \AA\right)$; iv) the rupture of these bonds leads to the formation of three O3, C5 and H6 pseudoradical centres; v) as TS is found at the end of Phase III, the high activation energy associated with this decomposition reaction in gas phase, $42.5 \mathrm{kcal} \mathrm{mol}^{-1}$, can mainly be related to the rupture of the O3-C4 (ca. $22.0 \mathrm{kcal} \mathrm{mol}^{-1}$ ) and C5-H6 (ca. $15.1 \mathrm{kcal} \mathrm{mol}^{-1}$ ) bonds of NEB 1, yielding two separated frameworks and a free hydrogen $\mathrm{H} 6$ atom stabilised by the C5 pseudoradical centre and the non-bonding $\mathrm{O} 1$ electron density; vi) the low electron population of the $\mathrm{V}(\mathrm{O} 3, \mathrm{C} 4)$ disynaptic basin together with the high EC demanded for the rupture of the first O3-C4 single bond suggests that this bond has a strong ionic character; vii) Group B, which comprises only Phase $I V$ and releases an MRE of $6.3 \mathrm{kcal} \mathrm{mol}^{-1}$, is mainly associated with the formation of the new O1-H6 bond at a O1-H6 distance of ca. $1.1 \AA$ by sharing part of the non-bonding electron density of the $\mathrm{O} 1$ oxygen with the free pseudoradical H6 hydrogen; and finally, viii) Group $C$, which comprises Phases $V$ and $V I$ and releases an MRE of $19.9 \mathrm{kcal} \mathrm{mol}^{-1}$, is mainly associated with the formation of the C4-C5 double bond at the nitroethylene framework and to the molecular electronic relaxation associated with the formation of nitroethylene 2 and benzoic acid $\mathbf{3}$. 
Fig. 5 Main bonding changes on going to TS. The rupture of the $\mathrm{C}-\mathrm{O}$ bond takes place heterolytically (red double-headed arrow), while the rupture of the $\mathrm{C}-\mathrm{H}$ bond takes place homolytically (two blue single-headed arrows)

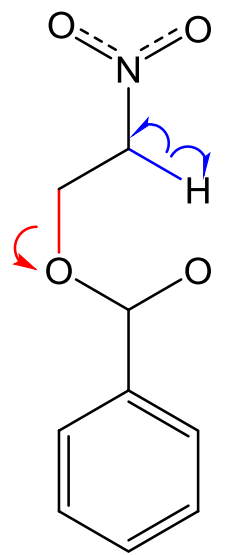

be considered a non-concerted one-step pseudocyclic reaction.

Acknowledgements This research was supported in part by PLGrid Infrastructure, by the Ministry of Economy and Competitiveness (MINECO) of the Spanish Government (CTQ2016-78669-P). RíosGutiérrez thanks the Spanish MINECO for a pre-doctoral contract cofinanced by the European Social Fund (BES-2014-068258).

Open Access This article is distributed under the terms of the Creative Commons Attribution 4.0 International License (http://creativecommons.org/licenses/by/4.0/), which permits unrestricted use, distribution, and reproduction in any medium, provided you give appropriate credit to the original author(s) and the source, provide a link to the Creative Commons license, and indicate if changes were made.

\section{Conclusions}

The molecular mechanism of the decomposition reaction of NEB $\mathbf{1}$ yielding nitroethylene $\mathbf{2}$ and benzoic acid $\mathbf{3}$ has been studied within the MEDT using DFT methods at the B3LYP/6-31G(d) computational level. This decomposition reaction takes place through a one-step mechanism. BET analysis of this reaction provides a complete characterisation of the electron density changes along the reaction. The reaction begins by the synchronous rupture of the $\mathrm{O} 3-\mathrm{C} 4$ and C5-H6 single bonds of NEB 1. These changes, which demand an energy cost of $37.1 \mathrm{kcal} \mathrm{mol}^{-1}$, are responsible for the high activation energy associated with this decomposition reaction. Interestingly, while the rupture of the first $\mathrm{O} 3-\mathrm{C} 4$ single bond takes place heterolytically, the rupture of the C5-H6 takes place homolytically, leading to the formation of a pseudoradical hydrogen atom. Formation of the C4-C5 double bond present in nitroethylene 2 takes place at the end of the reaction. In spite of the fact that this process releases an MRE of $19.9 \mathrm{kcal} \mathrm{mol}^{-1}$, it is not sufficient to overcome the energy demanded for the rupture of the $\mathrm{O} 3-\mathrm{C} 4$ and $\mathrm{C} 5-\mathrm{H} 6$ bonds, and consequently, the overall process is endothermic.

The six differentiated phases in which the IRC associated with this decomposition reaction is divided clearly point out the non-concerted nature of the bonding changes. This behaviour, together with the flux of the electron density on going from the reagent NEB 1 towards TS1 (see Fig. 5), makes it possible to reject a pericyclic mechanism. These reactions in which the six associated atomic centres are assembled in a more or less distortioned six-membered cyclic rearrangement at the TS but not necessarily bound have recently been categorised as pseudocyclic reactions. Consequently, the decomposition reaction of NEB 1 can

\section{References}

1. Notario R, Quijano J, Sanchez C, Velez E (2005) Theoretical study of the mechanism of thermal decomposition of carbonate esters in the gas phase. J Phys Org Chem 18:134-141

2. Alexander R, Kralert PG, Kagi RI (1992) Kinetics and mechanism of the thermal decomposition of esters in sediments. Org Geochem 19:133-140

3. Saido K, Kuroki T, Ikemura T, Kirisawa M (1983) Studies on the thermal decomposition of phthalate esters. J Anal Appl Pyrol 5:81-87

4. Bailey WJ, Barclay R (1956) Pyrolysis of esters. V. Mechanism of 1,4-Elimination. J Org Chem 21(3):328-331

5. Hurd BCh, Blunck FH (1938) The pyrolysis of esters. J Am Chem Soc 60(10):2419-2425

6. Barrett A, Graboski G (1986) Conjugated nitroalkenes: versatile intermediates in organic synthesis. Chem Rev 86:751-762

7. Ballini R, Castagnani R, Petrini M (1992) Chemoselective synthesis of functionalized conjugated nitroalkenes. J Org Chem 4:2160-2162

8. Jasiński R, Kubik M, Łapczuk-Krygier A, Kącka A, Dresler E, Boguszewska-Czubara A (2014) An experimental and theoretical study of the hetero Diels-Alder reactions between $(\mathrm{E})$ 2-aryl-1-cyano-1-nitroethenes and ethyl vinyl ether: one-step or zwitterionic, two-step mechanism? React Kinet Mech Cat 113(2):333-345

9. Perekalin VV, Lipina ES, Berestovitskaya VM, Efremov DA (1994) Nitroalkenes: conugated nitroalkenes. Wiley, New York

10. Kabalka GW, Varma RS (1987) Syntheses and selected reductions of conjugated nitroalkenes. Org Prep Proced Int 19:283-328

11. Jasiński R, Jasińska E, Dresler E (2017) A DFT computational study of the molecular mechanism of $[3+2]$ cycloaddition reactions between nitroethene and benzonitrile N-oxides. J Mol Model 23:13-21

12. Boguszewska-Czubara A, Łapczuk-Krygier A, Rykała K, Biernasiuk A, Wnorowski A, Popiołek L, Maziarka A, Hordyjewska A, Jasiński R (2016) Novel synthesis scheme and in vitro antimicrobial evaluation of a panel of (E)-2-aryl-1-cyano-1-nitroethenes. J Enz Inhib Med Chem 31:900-907

13. Al-Zereini W, Schuhmann I, Laatsh H, Helmke E, Anke H (2007) New aromatic nitro compounds from salegentibacter sp. T436, an Arctic Sea Ice Bacterium: taxonomy, fermentation, isolation and biological activities. J Antibiot 60:301-308

14. Clark NG, Croshaw B, Leggetter BE, Spooner DF (1974) Synthesis and antimicrobial activity of aliphatic nitro compounds. J Med Chem 17:977-981 
15. Herrera C, Vallejos GA, Loaiza R, Zeledon R, Urbina A, Sepulveda-Boza $S$ (2009) In vitro activity of thienyl-2-nitropropene compounds against trypanosoma cruzi. Mem Inst Oswaldo Cruz 104:980-985

16. Fisher E, Jourdan F (1883) Fischer Indole Synthesis. Chem Ber 16:1069-1075

17. Asinger F, Fell B, Collin G (1963) Über die Doppelbindungsisomerisierung bei höhermolekularen Olefinen, IV. Über den bindungsisomerisierenden Einfluß verschiedener Verbindungen auf n-Undecene. Eur. J Inorg Chem 96(3):716-735

18. Jasiński R, Kącka A (2015) A polar nature of benzoic acids extrusion from nitroalkyl benzoates: DFT mechanistic study. J Mol Model 21:59-65

19. Kącka A, Jasiński R (2016) A density functional theory mechanistic study of thermal decomposition reactions of nitroethyl carboxylates: undermine of "pericyclic" insight. Heteroatom Chem 27:279-289

20. Domingo LR, Saéz JA, Zaragozá RJ, Arnó M (2008) Understanding the participation of quadricyclane as nucleophile in polar $[2 \sigma+2 \sigma+2 \pi]$ cycloadditions toward electrophilic $\pi$ molecules. J Org Chem 73:8791-8799

21. Krokidis X, Noury S, Silvi B (1997) Characterization of elementary chemical processes by catastrophe theory. J Phys Chem A 101:7277-7282

22. Beck AD, Edgecombe KE (1990) A simple measure of electron localization in atomic and molecular systems. J Chem Phys 92:5397-5403

23. Thom R (1976) Structural stability and morphogenesis: an outline of a general theory of models. Inc, Reading, Mass, London-Amsterdam

24. Woodcock AER, Poston T (1974) A geometrical study of elementary catastrophes. Spinger, Berlin

25. Gilmore R (1981) Catastrophe theory for scientists and engineers. Dover, New York

26. Berski S, Andrés J, Silvi B, Domingo LR (2003) The joint use of catastrophe theory and electron localization function to characterize molecular mechanisms. A density functional study of the diels-Alder reaction between ethylene and 1,3-butadiene. J Phys Chem A 107:6014-6024

27. Polo V, Andrés J, Berski S, Domingo LR (2008) Understanding reaction mechanisms in organic chemistry from catastrophe theory applied to the electron localization function topology. J Phys Chem A 112:7128-7136

28. Andrés J, Berski S, Domingo LR, Polo V, Silvi B (2011) Describing the molecular mechanism of organic reactions by using topological analysis of electronic localization function. Curr Org Chem 15:3566-3575

29. Andrés J, González-Navarrete P, Safont V (2014) Unraveling reaction mechanisms by means of quantum chemical topology analysis. Int J Quantum Chem 114:1239-1252

30. Domingo LR (2016) Molecular electron density theory: a modern view of reactivity in organic chemistry. Molecules 21(10):1319-1333

31. Fukui K (1964) Molecular orbitals in Chemistry, Physics and Biology. Academic Press, New York, p 513

32. Geerlings P, De Proft F, Langenaeker W (2003) Conceptual density functional theory. Chem Rev 103:1793-1874

33. Domingo LR, Rios-Gutierrez M, Perez P (2016) Applications of the conceptual density functional theory indices to organic chemistry reactivity. Molecules 21(6):748-769

34. Bader RFW (1990) Atoms in molecules, a quantum theory. Claredon Press, Oxford
35. Johnson ER, Keinan S, Mori-Sanchez P, Contreras-Garcia J, Cohen J, Yang AW (2010) Revealing noncovalent interaction. J Am Chem Soc 132:6498-6506

36. Arnold RT, Smith GG, Dodson RM (1950) Mechanism of the pyrolysis of esters. J Org Chem 15(6):1256-1260

37. Domingo LR, Aurell MJ, Pérez P (2014) Understanding the polar mechanism of the ene reaction. A DFT study. Org Biomol Chem 12:7581-7590

38. Pérez P, Domingo LR (2015) A DFT study of inter- and intramolecular Aryne Ene reactions. Eur J Org Chem 13:2826-2834

39. Domingo LR, Rios-Gutierrez M, Chamorro E, Pérez P (2016) Aromaticity in pericyclic transition state structures? A critical rationalisation based on the topological analysis of electron density. Chem Sel 1(18):6026-6039

40. Domingo LR (2014) Why Diels-Alder reactions are non-concerted processes. J Chil Chem Soc 59:2615

41. Frisch MJ, Trucks GW, Schlegel HB, Scuseria GE, Robb MA, Cheeseman JR, Montgomery JA, Vreven TJ, Kudin KN, Burant JC, Millam JM, Iyengar SS, Tomasi J, Barone V, Mennucci B, Cossi M, Scalmani G, Rega N, Petersson GA, Nakatsuji H, Hada M, Ehara M, Toyota K, Fukuda R, Hasegawa J, Ishida M, Nakajima Y, Honda O, Kitao O, Nakai H, Klene M, Li X, Knox JE, Hratchian HP, Cross JB, Adamo C, Jaramillo J, Gomperts R, Stratmann RE, Yazyev O, Austin AJ, Cammi R, Pomelli C, Ochterski JW, Ayala PY, Morokuma K, Voth GA, Salvador P, Dannenberg JJ, Zakrzewski VG, Dapprich S, Daniels AD, Strain MC, Farkas MC, Malick DK, Rabuck AD, Raghavachari K, Foresman JB, Ortiz JV, Cui Q, Baboul AG, Clifford S, Cioslowski J, Stefanov BB, Liu G, Liashenko A, Piskorz P, Komaromi I, Martin RL, Fox DJ, Keith T, Al-Laham MA, Peng CY, Nanayakkara A, Challacombe M, Gill PMW, Johnson B, Chen W, Wong MW, Gonzalez C, Pople JA (2009) Gaussian 09 rev A.1 Gaussian Inc. Wallingford CT

42. Becke AD (1993) Density-functional thermochemistry. III. The role of exact exchange. J Chem Phys 98:5648-5652

43. Lee WY, Parr RG (1988) Development of the Colle-Salvetti correlation-energy formula into a functional of the electron density. Phys Rev B 37:785-789

44. Hehre WJ, Radom L, Schleyer PVR, Pople JA (1986) Ab initio molecular orbital theory. Wiley, New York

45. Fukui K (1970) Formulation of the reaction coordinate. J Phys Chem 74:4161-4163

46. González C, Schlegel HB (1990) Reaction path following in massweighted internal coordinates. J Phys Chem 94:5523-5527

47. González C, Schlegel HB (1991) Improved algorithms for recation path following: higher-order implicit algorithms. J Chem Phys 95:5853-5860

48. Noury S, Krokidis K, Fuster F, Silvi B (1999) Computational tools for the electron localization function topological analysis. Comput Chem 23:597-604

49. Silvi B (2002) The synaptic order: a key concept to understand multicenter bonding. J Mol Struct 614:3-10

50. Lewis GN (1916) The atom and the molecule. J Am Chem Soc 38:762-785

51. Reed AE, Weinstock RB, Weinhold F (1985) Natural population analysis. J Chem Phys 83:735-746

52. Reed AE, Curtiss LA, Weinhold F (1988) Intermolecular interactions from a natural bond orbital, donor-acceptor viewpoint. Chem Rev 88(6):899-926

53. Woodward RB, Hoffmann R (1969) The conservation of orbital symmetry. Angew Chem Int Ed Engl 8:781-853 